\title{
El Outsourcing, ¿una alternativa de ahorro o perjuicio laboral en México?
}

\author{
Outsourcing, an alternative for savings or labor damage in Mexico? \\ Víctor M. Piedra-Mayorga ${ }^{a}$, Miguel A. Vázquez-Alamilla ${ }^{b}$, Rafael Granillo-Macias ${ }^{c}$, Raúl \\ Rodríguez-Moreno ${ }^{d}$
}

\begin{abstract}
:
In this paper, the most relevant factors of outsourcing and their impact are analyzed. In Mexico, many companies offer subcontracting or outsourcing services that operate illegally or do not comply with the legal requirements that the Federal Labor Law stipulates, directly affecting workers, since there is a violation of their labor rights without any social benefit, Outsourcing well planned implies a series of benefits in favor of the company and workers, the Ministry of Labor and Social Welfare, assures that in Mexico the country there are almost five million people subcontracted, many a re in the informal economy, without registration in the Mexican Institute of Social Security as a beneficiary, a worrying situation because, in addition to this, under this labor system, taxes are evaded, unrealized jobs are simulated, ghost companies are created, few workers are registered, they abuse the underregistration and the need of workers, they estimates that 6 thousand outsourcing companies could be affecting workers It is due to illegal behavior. To date, the amount of tax evasion is calculated to be more than 21 million pesos per year. Undoubtedly, outsourcing is used by some companies to simplify or make human resources management easier, as well as to reduce time and costs for their business, but the worker, by not belonging directly to the company, can present a situation of exclusion and in case of affectation of their labor rights.
\end{abstract}

\section{Keywords:}

evasion of labor rights, subcontracting, jobs

\section{Resumen:}

En el presente trabajo se analizan los factores más relevantes de la subcontratación y su impacto. En México muchas empresas ofrecen servicios de subcontratación o de Outsourcing que operan ilegalmente o no cumplen con los requisitos legales que la Ley Federal del Trabajo estipula, afectando de manera directa a los trabajadores, ya que existe una violación a sus derechos laboral es sin ningún beneficio social, el Outsourcing bien planteado implica una serie de beneficios a favor de la empresa y trabajador es, la Secretaría del Trabajo y Previsión Social, asegura que en México el país hay casi cinco millones de personas subcontratadas, muchos se encuentran en la economía informal, sin registro en el Instituto Mexicano del Seguro Social como derechohabiente, situación preocupante porque además de ello bajo este sistema laboral se evaden impuestos, simulan trabajos no realizados, crean empre sas fantasmas, se registran pocos trabajadores, abusan del subregistro y de la necesidad de los trabajadores, se estima que 6 mil empresas de subcontratación pudieran estar afectando a los trabajadores debido a un comportamiento ilegal, a la fecha, el monto de evasión fiscal se calcula superior a los 21 millones de pesos anuales. Sin duda, el outsourcing es utilizado por alguna s empresas para simplificar o hacer más fácil la gestión de recursos humanos, así como reducir tiempo y costos para su negocio, pero el trabajador al no pertenecer de manera directa a la empresa puede llegar a presentar una situación de exclusión y en caso de afectación de sus derechos laborales

\section{Palabras Clave:}

Evasión de derechos laborales, subcontratación, empleos

\footnotetext{
Autor de Correspondencia, Universidad Autónoma del Estado de Hidalgo, https://orcid.org/0000-0002-1213-7632, Email: piedrinix@gmail.com

b Universidad Autónoma del Estado de Hidalgo, https://orcid.org/0000-0001-5349-7522, Email: m_vazquez_alamilla@ @otmail.com

c Universidad Autónoma del Estado de Hidalgo, Escuela Superior de Ciudad Sahagún, https://orcid.org/0000-0002-1015-667X, Email: rafaelgm@uaeh.edu.mx

d Universidad Autónoma del Estado de Hidalgo, https://orcid.org /0000-0001-8533-8024, Email: raromo@ hotmail.com 


\section{Introducción}

De acuerdo a la Ley Federal del Trabajo en México en el artículo 15 todos los empleados de las empresas de Outsourcing o tercerizadas deben de gozar de todos sus derechos laborales y la compañía subcontratada es la responsable de hacerlos valer, situación que tuvo mucho auge durante décadas en el gobierno mexicano, para generar más empleos, esta figura laboral se incluyó en la Ley Federal del Trabajo en el 2012, como un mecanismo laboral que permite la tercerización de servicios, pero debe estar cumpliendo con todas y cada una de las obligaciones legales que se contraen (Curiel, 2019), el objetivo de la investigación es analizar el impacto laboral, social y económico del outsourcing en los trabajadores y empresarios y sus efectos, se analizaron los efectos de esta forma de trabajar y algunas consecuencias detectadas en el aspecto fiscal y laboral.

\section{Escenarios de evasión}

- El primero es el llamado "estafa maestra", que involucra recursos públicos, para llevarla a cabo se crean diversas empresas inexistentes, son únicamente de "papel", empresas formadas y dirigidas por personas de bajos recursos que ponen como accionistas, los involucrados les otorgan una pequeña cantidad de dinero para que firmen como representantes, gestionen ante el Servicio de Administración Tributaria (SAT) su firma electrónica, y posteriormente apertura una cuenta bancaria. Su domicilio fiscal es un lugar inexistente o que no concuerda con las características o giro de la empresa, puede ser también un terreno baldío o en un lugar de escasos recursos y por esa empresa empiezan a mandar facturación millonaria, es la manera como empiezan a desviar recursos.

- El segundo, las factureras, en el que no hay recursos públicos involucrados, es el típico despacho de contadores o abogados, le envían a la supuesta empresa una factura, la pagan con IVA, se devuelve el dinero y se reparten en partes iguales el IVA (deducible).

- El tercer esquema es la tercerización u Outsoucing, se constituyen empresas para "ocultar" la relación laboral, no pagar Impuesto sobre la Renta (ISR), impuestos locales y otras prestaciones como Seguro Social.

- El cuarto esquema combina todos los otros e involucra lavado de dinero del crimen organizado (Keith, 2019).
La tercerización de obras y servicios o el llamado Outsourcing, se entiende como el servicio especializado que permite que los negocios se dediquen a su actividad principal sin distraerse en actividades no propias de la empresa, y cuya aplicación de forma responsable e informada puede generar grandes beneficios no sólo en un centro de trabajo, sino también en las economías de los países. En 2016 hacían uso de este servicio un 45\% de las empresas, para pasar a un $67 \%$ en 2018 . Este crecimiento en tan solo dos años es muy alto, tendencia que va en aumento, y más aún cuando se incluye el concepto de Outsou rcing disruptivo por el uso de la nube, usos de Tics, velocidad, adaptabilidad y acceso a nueva tecnología (Herrera, 2020).

El objetivo de la investigación es analizar y determinar los efectos del outsourcing en las empresas y en las relaciones laborales con los trabajadores, realizar propuestas y medidas preventivas para evitar consecuencias negativas.

El presente trabajo constituye una investigación aplicada, toda vez que está dirigida hacia la determinación de factores que inciden en los trabajadores y empresas el diseño que se utiliza en esta investigación es transaccional, ya que se recolectan datos en un solo momento, en un tiempo único y permite describir las variables y analizar su incidencia e interrelación entre las mismas, es una investigación no experimental porque no se manipulan las variables.

\section{Desarrollo}

De acuerdo al INEGI (2020), se contabilizan cerca de 5 millones de trabajadores bajo este esquema, esto ha generado un abuso de la figura legal de la subcontratación para emitir facturas falsas por servicios no realizados, que se puedan utilizar para evadir impuestos o lavar dinero, estas empresas son conocidas en México como factureros. En agosto de 2019, el Congreso Mexicano aprobó una ley de extinción de dominio, también pensada para ir en contra de estos factureros, con el objetivo de llevar a prisión preventiva o para congelar las cuentas de aquellos sospechosos, aunque también existen casos de empresas que no son de subcontratación y que no respetan los derechos de los trabajadores, ofreciendo salarios bajos, sin prestaciones y en ocasiones maltratando a los empleados, la ley regula y sanciona estos servicios especializados (es decir: los servicios que una empresa requiere contratar, pero no son parte de su modelo de negocios). México es el único país de habla hispana que utiliza los términos Outsourcing $y$ subcontratación de manera intercambiable, para referirse por igual a la prestación de un servicio, un empleo 
temporal o un trabajo de agencia, en esta relación laboral no existen derechos para los trabajadores ni hay opción de pelearlos, la empresa puede cambiar de nombre o domicilio constantemente, sin ningún impedimento legal, algunos ejemplos son en actividades turísticas, comerciales, de logística, de salud, call centers, o en las empresas que descansan a su personal para no pagar aguinaldo ni generen antigüedad sus trabajadores, entre otros, derivado de las condiciones comerciales cíclicas que se tienen cada año por el aumento de la demanda del servicio o ventas, el Outsourcing se desarrolla principalmente en la época decembrina en la que se incrementan sus ventas, situación que provoca una rotación constante del personal o el deseo de no trabajar en estas empresas por la inseguridad de formalizar la relación laboral, generando inmigración hacia otros estados del interior de la República Mexicana o Estados Unidos principalmente (Alcalde, 2020)

La subcontratación va de la mano con el empleo temporal, es decir, se ofertan empleos por un tiempo o proyecto determinado; normalmente producido por un pico de producción, proyecto específico o debido a la misma temporalidad comercial, pero no todo está relacion adocon la pérdida de empleos a finales de año, es un error atribuir este fenómeno a un servicio que ayuda a la generación de empleos formales, la subcontratación bien ejecutada debe cumplir con lo estipulado en la ley, es lógico que muchas empresas contraten más personal en ciertas épocas del año, para hacer frente a la temporada ya que se incrementa la demanda, pero también es lógico que al terminar el proyecto o la temporada las empresas no puedan mantener contratado a ese personal adicional, $y$ por ello existen empleos temporales, lo que no implica que no garanticen las prestaciones de ley a los trabajadores (Hernández, 2013).

En algunos casos para algunos trabajadores se convierte en su primer empleo, en la práctica las empresas en vez de contratar directamente a un conjunto de trabajadores, lo hace a través de agencias de empleo que se encarga de esta actividad, esto es muchas ocasiones una forma habitual de conseguir un empleo sin embargo, no todas las empresas realizan los procesos de reclutamiento y de administración de su personal de manera correcta, ya que la contratación la realiza un tercero de ahí el término tercerización, el actual gobierno presentó una iniciativa de ley para regular esta actividad ya que se está utilizando como una herramienta para generar fraudes fiscales, limitar o evadir los derechos de los trabajadores (Curiel, 2019). En la tabla 1 se presenta la población económicamente activa en México.
Tabla 1. Población económicamente en México 2020

\begin{tabular}{|c|c|c|c|c|}
\hline Año & $\begin{array}{c}\text { Población } \\
\text { Económicamente } \\
\text { Activa (PEA) }\end{array}$ & Ocupación & Desocupación & $\begin{array}{c}\text { Tasa de } \\
\text { desocupación }\end{array}$ \\
\hline 2016 & $52,505,443$ & $46,391,595$ & $6,113,848$ & 11.6 \\
\hline 2017 & $53,265,743$ & $47,622,856$ & $5,642,887$ & 10.6 \\
\hline 2018 & $54,645,562$ & $48,886,795$ & $5,088,457$ & 9.4 \\
\hline 2019 & $54,645,562$ & $50,184,280$ & $4,461,282$ & 8.2 \\
\hline 2020 & $55,290,762$ & $51,516,201$ & $3,774,561$ & 6.8 \\
\hline
\end{tabular}

Fuente: INEGI (2020)

El trabajo en régimen de subcontratación tiene a un patrón denominado contratista que ejecuta obras o presta servicios con sus trabajadores bajo su dependencia, a favor de un contratante, persona física o moral, la cual fija las tareas del contratista y lo supervisa en el desarrollo de los servicios o la ejecución de las obras contratadas, la Secretaria de Trabajo y Previsión Social en México obliga a los contratantes de servicios o empleadores de mano de obra a cumplir con las condiciones laborales legales apropiadas, el contratante se considerará patrón para todos los efectos legales, incluyendo las obligaciones que tiene sobre el otorgar seguridad social a sus trabajadores, las empresas tienen prohibido subcontratar al $100 \%$ de sus empleados (COFIDE, 2020).

Las condiciones comerciales cíclicas que se tienen cada año se da en muchos países, como parte de la competencia, para abaratar costos o permanecer en el mercado, durante el año existen fechas clave o que generan un incremento en la actividad comercial, económica y laboral, hay más contrataciones para cubrir el pico de producción, a este escenario comercial hay que sumar la pandemia sanitaria, lo que generó un incremento de la industria logística, para abastecer la demanda de entrega a domicilio de los bienes y servicios que se adquirieron durante el 2020, pero viviendo un mayor impacto a finales del año, ante la incertidumbre de saber si esta situación de aislamiento se mantendrá de forma permanente o no, muchas de estas empresas deciden contratar personal temporal por proyecto, pero también es lógico que al terminar el proyecto o la temporada las empresas no puedan mantener contratado a ese personal adicional (Hernández, 2013).

Los empresarios mexicanos han manifestado ante el gobierno su desacuerdo por la intención de eliminar este tipo de trabajo ya que genera beneficios importantes para la economía, otras empresas trabajan con un subregistro, reportando salarios menores de los que reciben realmente los trabajadores para evadir impuestos. Actualmente derivado de la pandemia del Covid-19, el Outsourcing o los descansos constantes durante y al final del año, las empresas pretenden evitar pagar aguinaldos o que los trabajadores generen antigüedad, sumado a esto se encuentra la automatización, robotización y teletrabajo 
situación que ha propiciado la pérdida de empleos formales.

Es necesario para bien de los trabajadores eliminar estas prácticas y con ello identificar cual es el verdadero punto de inflexión que está generando esta situación, en caso de que lo haya, o identificar qué parte del empleo formal siempre será temporal y entenderlo como una de las condiciones del mercado actual, en muchos casos, estos empleos temporales fungen como el primer empleo o una oportunidad de mejorar las condiciones económicas y laborales de muchas personas que en otra circunstancia formarían parte de la informalidad laboral, la iniciativa de ley propone poner fin a la práctica abusiva de subcontratación y la precariedad laboral, ya que cuando se cambia de empleador también cambian las prestaciones sociales y garantías laborales (STPS, 2017).

La iniciativa de ley propuesta desde el punto de vista empresarial y laboral criminalizar la subcontratación en sector público y privado, lo que generado una confrontación con los contratantes y empresas que han utilizado esta forma laboral de trabajo desde hace mucho tiempo sobre la precariedad y los abusos en el mercado laboral mexicano, que limitan el potencial de la segunda economía de América Latina. La pérdida de empleos a nivel global porcausa de la pandemia ha sido masiva y los Gobiernos en todo el mundo están buscando la manera de preservar fuentes de trabajo a través de distintas fórmulas de flexibilidad (Animal político, 2020).

\section{Ventajas y desventajas del Outsourcing}

De acuerdo a la Organización Internacional del Trabajo (OIT, 2020), conformada por trabajadores, gobiernos y empresas, creó el convenio 181, para evitar los abu sos de las agencias de trabajo y la protección de los derechos laborales. En 2014, la Organización para la Cooperación y el Desarrollo Económicos (OCDE) organizó consultas en las que participaron más de 80 países en desarrollo y las 20 economías más grandes del mundo para discutir cómo evitar el abuso de los tratados y medidas fiscales (Curiel, 2019). Las empresas no tienen la capacidad de incluir en sus nóminas a los trabajadores temporales que contrata a través de un tercero o una agencia. En México, el 57\% de la economía es informal y durante la pandemia más de cuatro millones personas han perdido su fuente de ingresos, formal o informal, con el Outsourcing una empresa destina sus recursos (le paga) a otra compañía externa que presta sus servicios de forma especializada para cumplir con ciertas actividades de la empresa, algunas actividades son (STPS, 2017):

\section{Soluciones de tecnología.}

2. Limpieza.

3. Salud.

4. Seguridad.

5. Servicio de atención al cliente.

6. Recursos humanos.

7. Contratación.

8. Contabilidad.

9. Vendedores.

10. Empleados de piso y mostrador.

11. Asesoría jurídica.

12. Mantenimiento.

13. Hotelería.

14. Restaurantes.

15. Call center.

16. Logística.

17. Entregas a domicilio.

La subcontratación está regulada por la Ley Federal del Trabajo en el artículo 15, donde la explica como una relación en la que existe un contratante y un contratista que presta servicios suministrando a su personal para que realice tareas específicas que fija la empresa y ésta misma debe supervisarlas, los beneficios o desventajas del sistema dependen de la forma en la que la empresa contratista y la prestadora de servicios llevan a cabo su relación comercial, a continuación se presentan las ventajas y desventajas del Outsourcing (véase Tabla 2).

\section{Tabla 2. Ventajas y desventajas del Outsourcing}

\begin{tabular}{|c|c|}
\hline Ventajas & Desventajas \\
\hline 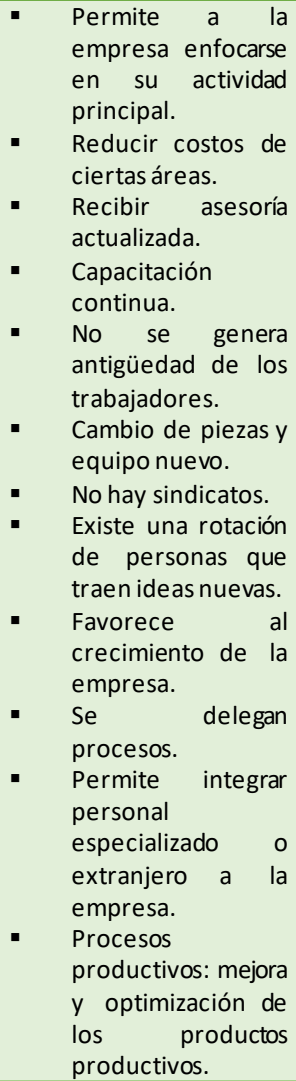 & $\begin{array}{l}\text { Vulnerabilidad en su información } \\
\text { confidencial de las empresas. } \\
\text { Fuentes externas a los negocios tienen } \\
\text { acceso a datos sensibles. } \\
\text { La comunicación puede ser menos } \\
\text { fluida, lo cual puede conllevar una } \\
\text { serie de malos entendidos. } \\
\text { Las fases de producción o los servicios } \\
\text { externalizados pueden verse } \\
\text { comprometida. } \\
\text { Una compañía que ofrece soluciones } \\
\text { de outsourcing trabaja a la vez con } \\
\text { diferentes proyectos, de modo que el } \\
\text { nivelde atención siempre es inferior al } \\
\text { de las compañías que únicamente se } \\
\text { dedican a ello. } \\
\text { Retrasos en los servicios ya que se } \\
\text { trata de incorporar una fase más en la } \\
\text { cadena de producción y/o } \\
\text { comercialización. } \\
\text { El trabajador no pertenece } \\
\text { estrictamente a la empresa, lo que } \\
\text { puede provocar mucha rotación y } \\
\text { evitar demandas laborales. } \\
\text { Se limita la oportunidad de } \\
\text { crecimiento y promoción. } \\
\text { Falta de mayores prestaciones } \\
\text { laborales. } \\
\text { Hay riesgo de caer con una simuladora } \\
\text { de outsourcing que no tenga el } \\
\text { registro establecido porla ley. } \\
\text { Si la subcontratación no es formal, los } \\
\text { empleados podrían no gozar de sus } \\
\text { derechos laborales. }\end{array}$ \\
\hline
\end{tabular}




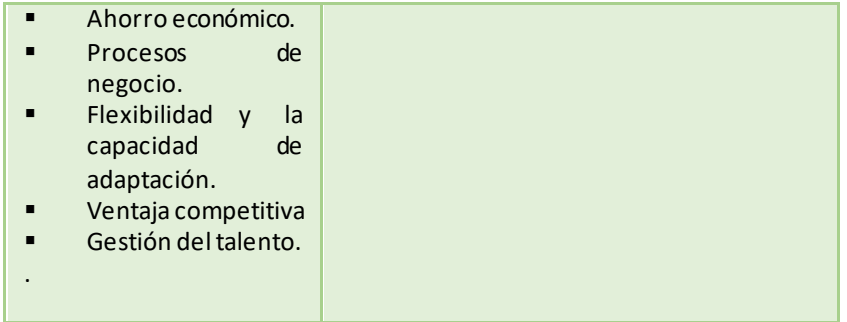

Fuente: STPS (2019)

\section{Características del Outsourcing}

El Consejo Nacional Agropecuario (CNA), la Confederación Patronal de la República Mexicana (Coparmex) y la Cámara Nacional de la Industria de la Transformación (Canacintra) rechazan la iniciativa del gobierno federal de legalizar este modelo laboral y exponen que la eliminación de la subcontratación fomentaría la pérdida de empleos, llevaría al cierre de micro, pequeñas y medianas empresas y se dañaría la competitividad del país. En México (2019) la Secretaría del Trabajo y Previsión Social (STPS) dio a conocer que existen 304 sucursales; y están involucradas 25 entidades federativas (Martínez, 2020). Para ofrecer estos servicios:

- La ley requiere que una empresa deberá obtener una autorización de la Secretaría del Trabajo y estar en un padrón público.

- Demostrar su actividad especializada o carácter especializado.

- Cumplir ante las instituciones de Seguridad Social y ante la Hacienda Pública.

Para contratar a una empresa externa para que se ocupe de alguno de los procesos productivos o servicios se debe considerar (véase Tabla 3)

Tabla 3. Características recomendables para contratarun Outsourcing.

\begin{tabular}{|ll|}
\hline - & $\begin{array}{l}\text { Analizar el estado económico y financiero de la organización } \\
\text { prestadora. }\end{array}$ \\
\hline - & $\begin{array}{l}\text { Analizar la información de otros usuarios para asegurarse que } \\
\text { cuenta con los elementos técnicos y humanos para hacer } \\
\text { frente a las obligaciones derivado de la contratación. }\end{array}$ \\
\hline - & $\begin{array}{l}\text { Asegurarse que realiza los pagos en tiempo, forma, y cumple } \\
\text { con las prestaciones sociales de los trabajadores. }\end{array}$ \\
\hline - & Analizar en profundidad a las candidatas. \\
\hline Alejarse de aquellas cuyo domicilio laboral y/o fiscal es \\
dudoso.
\end{tabular}

Fuente: KPMG (2018)

Una de las principales razones por la que muchos negocios optan por este sistema tiene que ver con los beneficios fiscales que ofrece en lo relativo a la deducción de impuestos, el hecho de que las empresas acudan cada vez más a la subcontratación de servicios está obligando a introducir algunas variaciones en el tratamiento judicial de estas complejas relaciones contractuales, este fenómeno ha sido tradicionalmente vigilado con lupa para evitar que fuera empleado por las compañías para eludir sus obligaciones laborales por medio de una cesión ilegal de trabajadores. en una reciente sentencia, el Tribunal Supremo ha flexibilizado algunos de los indicios de los que tradicionalmente se había servido para detectar el fraude, admitiendo, en cambio, que pueden ser circunstancias necesarias para lograr la adecuada coordinación considerando:

- El contratista debe facilitar una formación a los empleados de la subcontratista.

- Proporcionará a los trabajadores equipos informáticos y sistemas operativos.

- Supervisión.

- El control laboral es legal solo si la empresa informa al empleado

- El despido del empleado ludópata puede ser discriminatorio

- El finiquito no impide que la empresa pueda reclamar deudas al empleado

\section{Empresas en Outsourcing en México}

El comportamiento de las empresas frente a la reforma es heterogéneo y depende del tamaño de la empresa, hay estrategias que han sido más visibles frente a la reforma:

1. Despidos.

2. Reconfiguración de prestaciones.

3. Formalización de los empleos a costa de reducir plantillas laborales.

4. Trasladar los costos a los precios al consumidor.

5. Hay empresas que tenían a tres personas contratadas por Outsourcing porque les servía como un vehículo de supervivencia para permanecer en la informalidad.

6. Se trata de empresas que no utilizan el Outsourcing para sobrevivir o para evadir impuestos, lo usaban para administrar 0 ahorrarse el Pago de los Trabajadores en las Utilidades (PTU).

7. Como las empresas van a tener que formalizar a los trabajadores con la reforma, van a tener que pagar PTU, por consiguiente, van a reconfigurar, reducir o quitar otras prestaciones para compensar lo que signifique pagar PTU (Martínez, 2020).

A continuación, se muestran las empresas ubicadas en los diferentes estados mexicanos que trabajan bajo el esquema del outsourcing (Tabla 4). 
Tabla 4. Empresas en outsourcing en los estados

\begin{tabular}{|c|c|c|c|c|c|}
\hline$\underset{\text { N }}{\mathbf{N}}$ & Estado & $\begin{array}{c}\text { Número } \\
\text { de } \\
\text { empresa } \\
\mathrm{s}\end{array}$ & $\underset{\text { N }}{\mathbf{N}}$ & Estado & $\begin{array}{l}\text { Número } \\
\text { de } \\
\text { empresa } \\
s\end{array}$ \\
\hline 1 & $\begin{array}{c}\text { Aguascalient } \\
\text { es }\end{array}$ & 5 & 14 & Nayarit & 13 \\
\hline 2 & Coahuila & 15 & 15 & Oaxaca & 5 \\
\hline 3 & Colima & 1 & 16 & Puebla & 32 \\
\hline 4 & Chiapas & 3 & 17 & Querétaro & 36 \\
\hline 5 & Chihuahua & 4 & 18 & $\begin{array}{l}\text { Quintana } \\
\text { Roo }\end{array}$ & 5 \\
\hline 6 & Cd. México & 162 & 19 & $\begin{array}{l}\text { S. Luis } \\
\text { Potosí }\end{array}$ & 6 \\
\hline 7 & Durango & 1 & 20 & Sinaloa & 3 \\
\hline 8 & Guanajuato & 15 & 21 & Sonora & 2 \\
\hline 9 & Hidalgo & 2 & 22 & $\begin{array}{c}\text { Tamaulipa } \\
\text { s }\end{array}$ & 5 \\
\hline 10 & Jalisco & 34 & 23 & Tlaxcala & 1 \\
\hline 11 & $\begin{array}{l}\text { Estado de } \\
\text { México }\end{array}$ & 12 & 24 & Veracruz & 4 \\
\hline 12 & Michoacán & 1 & 25 & Yucatán & 2 \\
\hline 13 & Nuevo León & 1 & & & \\
\hline
\end{tabular}

Fuente: INEGI (2019)

\section{Leyes mexicanas afectadas}

Hay avances positivos en las negociaciones entre gobierno y sector privado en el tema de PTU (Participación de los trabajadores en las utilidades), empiezan a existir puntos de encuentro, se está afinando si el tope en el pago de PTU será de un mes o tres meses, las consecuencias de evadir impuestos han generado un agujero fiscal de alrededor de 250,000 millones de pesos en evasión de ISR e IVA. Un fraude al Instituto Mexicano del Seguro Social (IMSS) estimado en 21,000 millones de pesos y casi cinco millones de personas subcontratadas por terceros que en realidad trabajan para una empresa que no se hace responsable. La iniciativa para prohibir la subcontratación, incrementará más de $25 \%$ los costos de sectores completos de la economía que recurren a este esquema para limitar costos. Para el gobierno federal representa el combate a un esquema que hizo fortunas rápidas para una tribu de despachos fiscales o laborales, que explotaron agujero de las siguientes leyes (Figura 1)

\section{Figura 1. Leyes afectadas por el Outsourcing}

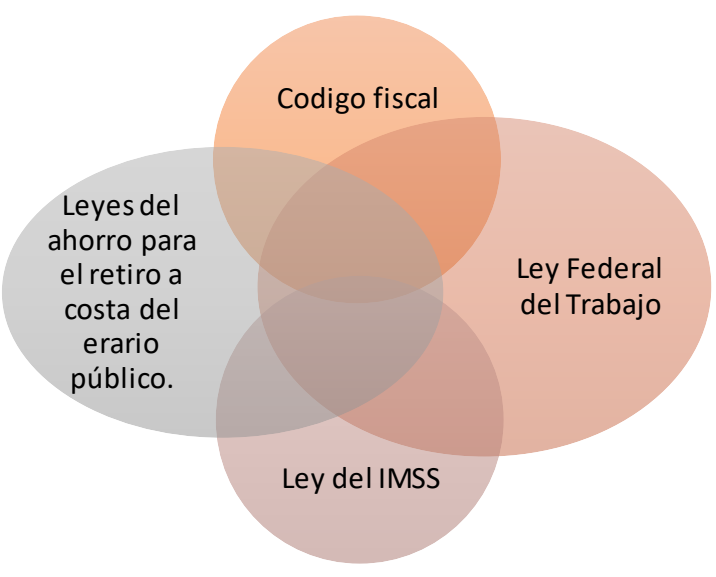

Fuente: Martínez (2020)

Sin embargo, la iniciativa presentada al Congreso no contempla la falta de liquidez en las empresas ante la crisis económica provocada por el COVID 19, el hecho de que el reparto de utilidades frena la competitividad de las empresas mexicanas en el contexto global, o que muchos negocios pagan doble por la salud de sus empleados: un seguro privado y un IMSS que no puede cubrir las necesidades de todos, se debe cumplir la ley, se debe acabar con años de excesos, la ley sí contempla esquemas de contratación especializada, por ejemplo, para servicios de limpieza u otros ajenos a la naturaleza de la empresa (IMSS, 2020).

La reforma del Outsourcing es para detener las prácticas abusivas, que van en detrimentos de derechos laborales como el acceso a una pensión digna, obtención de prestaciones sociales y seguridad en el empleo, el Servicio de Administración Tributaria (SAT), donde se calcula que la defraudación fiscal vía factureras es de cerca de 500,000 millones de pesos al año, en el IMSS, que son 21,000 millones de pesos por concepto de cuotas y otros 250,000 millones de pesos fiscales, sumando IVA e ISR. El cálculo es que 5 millones de personas están trabajando bajo este esquema de subcontratación (Martínez, 2020), con los siguientes beneficios para el patrón:

- Como patrón (al utilizar la terciarización ilegal) al trabajador le sea más difícil demandar.

- Se disfraza la relación laboral.

- La antigüedad del empleo no se genera porque está dado de alta en otra empresa. 
- No se paga PTU.

- Genera un ahorro por no pagar.

- El riesgo que tiene el empresario que contrata estos servicios de Outsourcing es que es una factu rera; de acuerdo a la lista del artícu lo 69B del Código Fiscal (empresas que facturan operaciones simuladas y empresas que deducen operaciones simuladas) y le van a quitar los beneficios fiscales al comprobante fiscal y el ISR a deducir se va a tener que pagar, el IVA no es acreditable, su supuesto ahorro tiene una tasa potencial de $25 \%$ anual de costo.

El Outsourcing, o la subcontratación laboral, hoy adquiere el nombre de contratación de servicios especializados, o de obra especializada, ya que no se puede tener una tercerización o servicios especializados algo que tieneque ver con el objeto social de la organización, es decir, en un despacho de abogados, no puedo tener abogados de una empresa de servicios especializados, se puede tener los servicios de limpieza, al que repara las computadoras en servicios especializados, pero no a los abogados.

- Cuando se va a contratar, se pide la constancia y los pagos, y para poder hacer deducible la factura, hay que acreditar la constancia y que está al corriente en sus obligaciones.

- No se descarta que los trabajadores que se vayan a contratar una vez que entre en vigor la reforma, pero al no haber operaciones simuladas, habrá certeza en cuanto a los derechos laborales.

- Se va a ganar a lo mejor menos, pero ya vas a tener un fondo de pensión, seguridad social y cosas que antes no se tenía.

- La ley entrará en vigor al día siguiente de su publicación en el Diario Oficial de la Federación (DOF). Va a haberun tiempo de transición porque va a haber un tiempo de registro para las empresas de servicio especializado.

- Esta reforma tiene que ir de la mano con empresarios.

En los primeros tres meses del año, y en espera de cambios en materia de subcontratación, las empresas han empezado a trazar diferentes escenarios (IMSS, 2020), entre los que se encuentra, asumir el $10 \%$ de los costos para contratar de manera directa a los trabajadores, (vease Figura 2).
Figura 2. planes preventivos de los empresarios ante la legalización del outsourcing

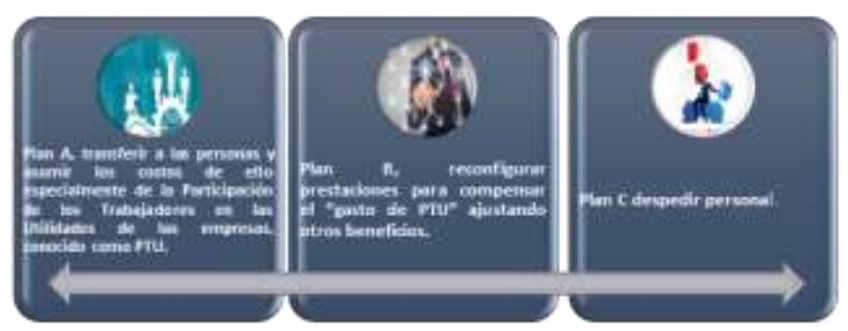

Fuente: STPS (2020)

Es buen momento para que las empresas se regularicen, todas estas compañías que han decidido utilizar la subcontratación de manera legal, y esta posibilidad de establecer un tope a la PTU le puede dar salida a la iniciativa, como también ayudaría mucho que se estableciera un periodo razonable para la entrada en vigor la reforma, además de que la autoridad ya está tomando acciones de perseguir aquellas compañías que utilizan el Outsourcing como un esquema de subcotización o de evasión fiscal, hay una incertidumbre, pero también se ha empezado a notar un cambio en las empresas que han delineado sus propias estrategias, no siempre la legislación va con la realidad, las empresas se tienen que adelantar a los ajustes, de lo contrario corren el riesgo de paralizarse (Martínez, 2020).

\section{Conclusiones}

Es necesario una vigilancia constante por parte del gobierno y perseguir los comportamientos inadecuados; eso podría contribuir a que haya mejores decisiones y concordia en las relaciones laborales. También es cierto que aún en el peor de los escenarios de esta iniciativa, va a tomar tiempo y le va a dar un cierto margen de semanas o meses a los empleadores para reaccionar. El talento es escaso, se está gestando una nueva forma de conceptualizar el trabajo (en particular, con la llegada de la Cuarta Revolución Industrial que demanda nuevas competencias), la convivencia de hasta cuatro generaciones en las organizaciones, el uso de las tecnologías de la información, internacionalización del mercado laboral y el incremento del Outsourcing (Ibarra \& González, 2020).

Desde la reforma a la Ley Federal del Trabajo (LFT) en 2012, por primera vez se introdujo la regulación de la subcontratación, con lo cual se establecieron las bases para entender la llamada Descentralización productiva, o bien, la búsqueda de mejores opciones para hacer mejor 
las cosas. El marco normativo que regula la subcontratación, se rige por los artículos 15-A, 15B, 15C, y $15 \mathrm{D}$ de la LFT, que la define como el medio por el cual un patrón denominado contratista, ejecuta obras o presta servicios con sus trabajadores bajo su dependencia, a favor de un contratante, persona física o moral, la cual fija las tareas del contratista y lo supervisa en el desarrollo de los servicios o la ejecución de las obras contratadas. Con esta reforma, la figura de la subcontratación generó un mecanismo para que las empresas puedan llevar a cabo sus actividades productivas, sin tener que distraer recursos que por su naturaleza no estén directamente relacionados con la materia de producción o el objetivo que persiguen, delegando en un tercero denominado contratista tareas que pueden ser especializadas, o bien, que no impactan directamente en las actividades que se desarrollan en el centro de trabajo (IMSS, 2020). El artículo 15-A determina las condiciones entre las que se encuentran:

- No poder abarcar la totalidad de las actividades, iguales o similares que se desarrollan en el centro de trabajo.

- El deber justificar por su carácter especializado,

- No poder comprender tareas iguales o similares a las que realizan el resto de los trabajadores al servicio del contratante.

El modelo de subcontratación ilegal hoy tiene a trabajadores con salarios por debajo del salario real, sin percibir utilidades y sin ningún ben eficio social, es tiempo de desmitificar la subcontratación como un modelo de fraude o simulación y también revisar las bondades y ventajas que esta conlleva, pues la tercerización permite a las empresas cumplir con su objeto y generar más oportunidades de empleo, identifica al talento y poner al alcance de todos mayores y mejores bienes y servicios (lbarra \& González , 2020).

Lo más importante es generar un equilibrio que permita a las empresas el uso de esta vía para elevar la productividad y hacer más atractiva la inversión;y, por otro lado, se puedan garantizar los derechos de los trabajadores y no caer en la simulación, pero en ambos casos siempre cuidando la dignidad de la persona, el problema es que hay empresas que están fuera de la ley, si México realmente quiere proteger los derechos de los trabajadores, podría empezar por ratificar el convenio 181 de la OIT: a pesar de ser miembro de la OIT y de haber firmado el protocolo en 1997, el país no lo ha ratificado ni actualizado, según los empresarios la iniciativa de ley para acabar con el outsourcing no incluye provisiones para atacar lo que el gobierno dice que quiere atacar, simplemente da consecuencias de multas, de pagos de ilícitos penales a quiénes incumplen, la legislación en materia laboral, de seguridad social y fiscal están ya establecidas y con consecuencias para quienes no cumplan, lejos de traer desempleo, va a ir construyendo un mercado laboral más equitativo, más justo, pero también más productivo (Alcalde, 2020).

\section{Referencias}

Alcalde (2020). Evaden cerca de 21 mil millones de pesos. Recuperado de https://www.elfina nciero.com.mx/economia/empresas-que-empleansubcontratacion-ilegal-evaden-cerca-de-21-mil-millones-de-pesosa calde

Animal político (2020), La estafa maestra. Recuperado de https://www.animalpolitico.com/estafa-maestra/

COFIDE (2020) Conoce las normas legales del régimen de subcontratación. Recupera do de Conocer las normas lega les del régimen de $\underline{\text { subcontratación (cofide.mx) }}$

Curiel (2020). La reforma a la Ley Federal del Trabajo en materia de subcontratación en México. Recuperado de C: IUsers\DATOS\Downloads\189-365-1-SM.pdf

Hernández \& Hernández \% Mendieta (2013). Modelo de rotación de personal y prácticas organizacionales. Recuperado de C: \Users\DATOS\Downloads\44369-Texto del art Â-culo-68697-3-1020140328.pdf

Herrera (2020). El outsourcing en México. Recuperado de El outsourcing en México. (revistafortuna.com.mx)

Ibarra \& González (2020). La flexibilidad laboral como estrategia de competitividad y sus efectos sobre la economía, la empresa y el mercado de trabajo. Recuperado de http://www.scielo.org.mx/scielo.php?script=sci_arttext\&pid=S018610422010000200003

IMSS (2020). Outsourcing, información general. Recuperado de Outsourcing, información general.

INEGI (2020). Estadísticas Nacionales. Recuperado de Censo Población y Vivienda 2020 (inegi.org.mx)

Keith (Víctor M. Piedra) (14 ago. 2019). ¿Qué es la estafa maestra y por qué sacude a México? Video MP4. Recuperado de (1045)iQué es la estafa maestra y porqué sacude a México? - YouTube

KMPG (2018). El outsourcing, 10 puntos cla ve para llevarlo a cabo. Recuperado de El outsourcing, 10 puntos clave para llevarlo a cabo KPMG México (home.kpmg)

Martínez (2020). Nuevo acuerdo sobre outsourcing divide al sector empresarialRecupera do de https://www.eleconomista.com.mx/empresas/Nuevo-acuerdo-sobreoutsourcing-divide-al-sector-empresarial-20201209-0041.html

OIT (2020). C181 - Convenio sobre las agencias de empleo privadas, 1997. Recuperado de Convenio C181 - Convenio sobre las agencias de empleo privadas, 1997 (núm. 181) (ilo.org)

STPS (2017). Seguridad y Salud en el Trabajo en México: Avances, retos y desafíos. Recuperado https://www.gob.mx/cms/uploads/attachment/file/279153/LibroSeguridad y salud en el trabajo en Me xicoAvances retos y desafios Digital .pdf 